Scientia Agraria Paranaensis - Sci. Agrar. Parana.

ISSN: 1983-1471 - Online

\title{
ANÁLISE ESTRUTURAL E DINÂMICA DE Gymnanthes klotzschiana (Müll. Arg.) EM UM FRAGMENTO DE FLORESTA OMBRÓFILA MISTA
}

\author{
Wesllen Schuhli Kieras ${ }^{1}$; Yuri Accioly²; Sebastião do Amaral Machado³ \\ SAP 16267 Data envio: 15/02/2017 Data do aceite: 05/07/2017 \\ Sci. Agrar. Parana., Marechal Cândido Rondon, v. 17, n. 1, jan./mar., p. 71-79, 2018
}

\begin{abstract}
RESUMO - A Gymnanthes klotzschiana é uma espécie arbórea pioneira característica das planícies aluviais da Floresta Ombrófila Mista, importante para a conservação das matas ciliares. Portanto este trabalho tem como objetivo analisar a estrutura e a dinâmica de G. klotzschiana em um fragmento de Floresta Ombrófila Mista. Os dados utilizados na pesquisa provêm de um censo (inventário 100\%) realizado nos anos de 2007, 2010 e 2013 no Capão da Engenharia Florestal, situado na Universidade Federal do Paraná, Curitiba (PR), com área total de 15,2 ha. As medições foram realizadas em intervalos de 3 anos, sendo mensuradas e identificadas todas ás árvores com circunferência à altura do peito superiores a $30 \mathrm{~cm}$. As análises estruturais foram realizadas com base nos parâmetros populacionais por espécie e a dinâmica foi obtida por meio do acompanhamento do crescimento, ingresso e mortalidade entre os períodos de medição. Os resultados mostram um aumento de indivíduos entre as três medições, passando de 120 para 256 indivíduos, consequentemente, houve um incremento considerável em área basal entre as medições, de $3,26 \mathrm{~m}^{2}$ para $6,2 \mathrm{~m}^{2}$. A taxa de incremento periódico anual em diâmetro aumentou de $0,31 \mathrm{~cm} / \mathrm{ano}$ para $0,34 \mathrm{~cm} / \mathrm{ano}$, e o incremento periódico anual em área transversal majorou de $0,0280 \mathrm{~m}^{2} \mathrm{ha}^{-1} \mathrm{para}$ $0,0397 \mathrm{~m}^{2} \mathrm{ha}^{-1}$. A taxa de ingresso aumentou gradativamente, enquanto não houve mortalidade no período de medições. A G. klotzschiana possui alto valor de importância para a Floresta Ombrófila Mista, bem como uma dinâmica que favorece o desenvolvimento de outras espécies.
\end{abstract}

Palavras-chave: branquilho, crescimento, estrutura horizontal, ingresso, mortalidade.

\section{DYNAMICS AND STRUCTURAL ANALYSES OF Gymnanthes klotzschiana (Müll. Arg.) IN A MIXED OMBROPHILOUS FOREST FRAGMENT}

\begin{abstract}
The Gymnanthes klotzschiana is a pioneer tree species characteristic of the alluvial plains of Mixed Ombrophilous Forest, important for the conservation of the riparian forests. Therefore, this work aims to analyze a structure and dynamics of G. klotzschiana in a fragment of Mixed Ombrophilous Forest. The used came from a senso at in the years 2007, 2010 and 2013, located in the Botanical Gaden, Curitiba (PR), Brazil, with a total area of 15.2 ha. Measurements were performed at intervals of 3 years, and all trees with diameter at breast height greater than $10 \mathrm{~cm}$ were measured and identified. Structural analyzes were performed based on the population parameters by species, dynamics was obtained monitoring the growth, ingrowth, and mortality between the measurement periods. The results show a constant increase between three measurements, going from 120-256 individuals; as a consequence, there was a considerable increasing in basal area between measurements going from $3.26 \mathrm{~m}^{2}$ to $6.2 \mathrm{~m}^{2} \mathrm{ha}^{-1}$. An annual increment rate of $0.31 \mathrm{~cm} /$ year to $0.34 \mathrm{~cm}$ year, and the periodic annual increment in cross-sectional area increased from $0.0280 \mathrm{~m}^{2} \mathrm{ha}^{-1}$ to $0.0397 \mathrm{~m}^{2} \mathrm{ha}^{-1}$. There was a relative increasing for the coverage values and for the importance values between measurement. It is concluded that G. klotzschiana has a high value of importance for a Mixed Ombrophilous Forest, as well as a dynamic that favors the development of other species.
\end{abstract}

Key words: branquilho, growth, horizontal structure, ingrowth, mortality.

\section{INTRODUÇÃO}

A característica mais marcante da Floresta Ombrófila Mista é a presença de Araucaria angustifolia (Bert.) Ktze., conhecida popularmente como pinheiro-doparaná. Também compreende espécies dos gêneros Drymis e Podocarpus, ocorrendo em associações diversificadas com espécies das famílias Lauraceae, Myrtaceae, Aquifoliaceae, Anacardiaceae, Flacourtiaceae, Euphorbiaceae e Sapindaceae, entre outras. Esta tipologia florestal tem sido considerada um dos mais notáveis em termos de valor ecológico, por abrigar espécies típicas e atributos biológicos únicos em todo o planeta (SEGER, 2005).

A Floresta Ombrófila Mista é subdividida em quatro fisionomias principais segundo Veloso et al. (1991): aluvial, submontana, montana e altomontana, sendo que a principal diferença entre elas é a altitude, tornando-se crescente da aluvial para a altomontana. A fisionomia

${ }^{1}$ Graduando, Engenharia Florestal, Universidade Federal do Paraná (UFPR). Av. Prefeito Lothário Meissner, n.632, Jardim Botânico, CEP 80210-170, Curitiba, Paraná, Brasil. E-mail: wesllenkieras@gmail.com

${ }^{2}$ Engenheiro Florestal, Universidade Federal do Paraná (UFPR). Av. Prefeito Lothário Meissner, n.632, Jardim Botânico, CEP 80210-170, Curitiba, Paraná, Brasil.

${ }^{3}$ Engenheiro Florestal, Professor Sênior, Departamento de Ciências Florestais da Universidade Federal do Paraná (UFPR). Av. Prefeito Lothário Meissner, n.632, Jardim Botânico, CEP 80210-170, Curitiba, Paraná, Brasil. E-mail: samachado@ufpr.br 
aluvial é caracterizada por solos altamente hidromórficos, onde algumas espécies como a Gymnanthes klotzschiana e a Schinus terebinthifolius ocorrem com muita frequência.

$$
\text { G. klotzschiana é importante para a }
$$
sobrevivência de outras espécies, pois fornece alimentos para alguns pássaros e peixes que se alimentam das sementes que caem nos rios e lagos, além de ser uma espécie com alta capacidade de desenvolvimento em regiões hidromórficas, principalmente as margens dos rios. A espécie apresenta dispersão balistocórica, ictiocórica, por peixes, especialmente o lambari (Astyanax spp.); e ornitocórica, especialmente por rolinhas (Columbina minuta) (Carvalho, 2003).

Pertence à família Euphorbiaceae, é vulgarmente conhecida como branquilho, sendo uma espécie característica das planícies aluviais da Floresta Ombrófila Mista e um dos elementos que melhor caracteriza o estrato arbóreo das florestas ciliares encontradas em várzeas planas do primeiro e do segundo planalto paranaense (SILVA et al., 1992). Ocorre naturalmente desde o Rio de Janeiro e Minas Geras até o Rio Grande do Sul, abrangendo países como o Paraguai, Uruguai e Argentina, nas matas ciliares de várias formações florestais (LORENZI, 1992)

Segundo Narvaes et al. (2008), essa tipologia florestal vem sendo explorada de forma inadequada pela retirada de madeira de valor comercial de forma clandestina, ou pela substituição da floresta para o uso do solo para o cultivo agrícola, exceto em pequenas áreas onde o relevo não o favorece.

Diante deste cenário, é imprescindível desenvolver pesquisas aliadas a conservação e manejo de espécies com alto valor de importância para a tipologia florestal de interesse. A conservação e o manejo destas espécies provêm das informações obtidas a partir dos levantamentos fitossociológicos (análise estrutural) e da avaliação de suas respectivas dinâmicas de crescimento. Contudo, um grande número de espécies não possui pesquisas que comprovem sua importância ecológica em seu habitat, evento que ocorre com a G. klotzschiana.

Este trabalho visa aumentar a gama de informações inerentes a G. klotzschiana com o intuito de proporcionar melhores condições de conservação e manejo da espécie na Floresta Ombrófila Mista Aluvial.

Diante do exposto, objetivou-se com o presente trabalho descrever a estrutura e a dinâmica de Gymnanthes klotzschiana (Müll. Arg.) em um fragmento de floresta ombrófila mista, correlacionando o seu crescimento com outras espécies, além de trazer informações inerentes a espécie, tais como a relação hipsométrica, tendo como base à sua importância na Floresta Ombrófila Mista Aluvial, buscando preencher em partes a falta de informação sobre o desenvolvimento desta espécie.

\section{MATERIAL E MÉTODOS}

\section{Caracterização da área de estudo}

A área de estudo compreende um fragmento da Floresta Ombrófila Mista, conhecido como Capão da Engenharia Florestal, situado no município de Curitiba
(PR), entre as coordenadas $25^{\circ} 26^{\prime} 05^{\prime}$ '-25'27'33' $\mathrm{S}$ e 49 $14^{\prime} 16^{\prime}$ ' $-49^{\circ} 14^{\prime} 33^{\prime \prime} \mathrm{W}$, com aproximadamente $900 \mathrm{~m}$ de altitude. O clima da região segundo a classificação de Köppen é $C f b$ (subtropical úmido mesotérmico) com verões frescos e invernos com geadas frequentes, sem estação de seca. As temperaturas médias anuais nos meses mais quentes e frios são inferiores a $22^{\circ} \mathrm{C}$ e $18^{\circ} \mathrm{C}$, respectivamente, sendo a temperatura média anual de $17^{\circ} \mathrm{C}$ (RONDON NETO et al., 2002).

As respectivas médias anuais de umidade relativa do ar e precipitação nessa região são iguais a $85 \%$ e 1.300 a $1.500 \mathrm{~mm}$, sem ocorrência de deficiência hídrica ao longo do ano (MAACK, 1981).

A área do remanescente é de aproximadamente 15,24 ha, dos quais 12,96 ha são ocupados pela Floresta Ombrófila Mista (RONDON NETO et al., 2002). Os solos presentes no fragmento foram classificados como Cambissolo Húmico Álico, Cambissolo Húmido tb Distrófico, Cambissolo gleissólico, Gleissolo Háplico e Neossolo Flúvico gleissólico. A fisionomia em que a $G$. klotzschiana se insere no fragmento é aluvial, com frequentes inundações entre os meses de outubro a fevereiro, caracterizado pela baixa diversidade de espécies (SANTOS, 2014).

\section{Coleta de dados}

Toda a área do remanescente foi dividida em blocos de $50 \mathrm{~m}$ x $50 \mathrm{~m}$ totalizando 70 blocos, sendo que cada bloco foi dividido em cinco sub-blocos de $500 \mathrm{~m}^{2}$ $(10 \mathrm{~m} \times 50 \mathrm{~m})$. Esse procedimento foi adotado para facilitar o georreferenciamento das árvores. Dentro dos sub-blocos, mediram-se todos os indivíduos com circunferência à altura do peito $(\mathrm{CAP}) \geq 30 \mathrm{~cm}$, marcandose o ponto de medição da circunferência com tinta azul. Cada árvore recebeu uma plaqueta numerada dentro do bloco ao qual pertencia (AUGUSTYNCZIK, 2011).

As medições de todas as árvores foram realizadas em intervalos de três anos, sempre no mês de julho. A primeira mensuração foi realizada no ano de 2007, enquanto que no ano de 2013 foi obtida a última mensuração utilizado para este trabalho, contemplando três repetições (2007, 2010 e 2013) para análise da dinâmica.

Para fins do levantamento, para todas as árvores foram coletadas as informações:
a) espécie,
b) CAP a $1,3 \mathrm{~m}$
c) coordenadas $(\mathrm{X}, \mathrm{Y})$ cartesianas de cada árvore,
d) dossel (inferior, médio ou superior),
e) qualidade do fuste (inclinado, tortuoso, levemente tortuoso ou reto) e

f) estado fitossanitário (sem infestação, com infestação ou com infestação avançada).

Especialmente para a espécie Gymnanthes klotzschiana, foi realizado a mensuração da altura total em janeiro de 2016, com o auxílio de réguas graduadas de $12,5 \mathrm{~m}$. 


\section{Distribuição diamétrica}

Para a análise da estrutura diamétrica, considerouse a frequência dos diâmetros em classes de amplitude de 5 $\mathrm{cm}$, devido à baixa taxa de crescimento da espécie. Dessa forma, a primeira classe foi composta por indivíduos que apresentaram diâmetro à altura do peito entre 10 e $15 \mathrm{~cm}$, da mesma forma que a última classe foi composta por indivíduos de 40 a $45 \mathrm{~cm}$, totalizando assim oito classes diamétricas.

\section{Análise estrutural}

Para a análise estrutural foram utilizados apenas estrutura horizontal proposto por Mueller-Dombois; Ellenberg (1974), levando em consideração a abundância, densidade, dominância, frequência, valor de cobertura e valor de importância.

Todos esses parâmetros foram utilizados para efeito de comparação entre todas as espécies presentes no capão, onde estabeleceu um ranking das espécies de maior valor de importância. Esses resultados são dinâmicos ao longo dos anos, devido principalmente ao grande número de ingressos, além de espécies de rápido crescimento.

\section{Dinâmica}

$\mathrm{O}$ incremento em diâmetro e em área basal foram obtidos no crescimento das árvores mensuradas em três ocasiões, levando em consideração apenas os indivíduos que permaneceram vivas em todo o período avaliado. Portanto, foram descritos os incrementos ocorridos entre 2007-2010 e 2010-2013. Os incrementos periódicos (IP) e periódico anual (IPA) foram obtidos através das seguintes fórmulas de incremento (1):

$$
\begin{aligned}
& I P_{d}=d_{f}-d_{i}(1) \\
& I P A_{d}=\frac{I P_{d}}{P} \text { (2) } \\
& I P_{G}=G_{f}-G_{I} \text { (3) } \\
& I P A_{G}=\frac{I P_{G}}{P} \\
& \text { Onde: }
\end{aligned}
$$

$I P_{d}=$ incremento periódico em diâmetro $(\mathrm{cm})$,

$I P A_{d}=$ incremento periódico anual em diâmetro ( $\left.\mathrm{cm} / \mathrm{ano}\right)$,

$d_{f}=$ DAP no final do período de crescimento avaliado (cm),

$\mathrm{d}_{i}=$ DAP no início do período de crescimento avaliado $(\mathrm{cm})$,

$I P_{G}=$ incremento periódico em área basal $\left(\mathrm{m}^{2} \mathrm{ha}^{-1}\right)$,

$G_{f}=$ área basal no final do período avaliado $\left(\mathrm{m}^{2} \mathrm{ha}^{-1}\right)$,

$G_{i}=$ área basal no início do período avaliado $\left(\mathrm{m}^{2} \mathrm{ha}^{-1}\right) \mathrm{e}$

$P=$ intervalo de medição (anos).

A dinâmica também foi avaliada com base na taxa de ingresso e mortalidade entre os períodos de mensurações.

\section{Processamento dos dados}

A relação hipsométrica foi ajustada por meio de modelagem a partir dos dados de diâmetro e altura resultante da mensuração de 2016 (Tablea 1). Há vários modelos descritos na literatura que estimam a variável altura com base nos dados observados de DAP ou que ainda estimam a altura a partir de curvas hipsométricas ajustadas.

TABELA 1 - Modelos matemáticos ajustados para relação hipsométrica de Gymnanthes klotzschiana.

\begin{tabular}{ccc}
\hline & Modelo & Autores \\
\hline 1 & $h=\beta_{0}+\beta_{1} l$ lnd & Henricksen \\
2 & $h=\beta_{0}+\beta_{1} d_{+} \beta_{2} d^{2}$ & Trorey \\
\hline
\end{tabular}

${ }^{*} \mathrm{~h}=$ altura, $\mathrm{d}=$ diâmetro a $1,30 \mathrm{~m}$ do solo, $\beta_{0}, \beta_{1}=$ coeficientes de regressão.

Para a escolha do melhor modelo matemático é necessário analisar o coeficiente de determinação ajustado $\left(\mathrm{R}^{2}{ }_{\mathrm{aj}}\right.$ ), o erro padrão da estimativa $(\mathrm{Syx} \%)$, valor de $\mathrm{F}$ calculado $\left(\mathrm{F}_{\text {cal }}\right)$ e a análise gráfica de resíduos.

\section{RESULTADOS E DISCUSSÕES \\ Distribuição diamétrica}

A distribuição diamétrica da Gymnanthes klotzschiana incide sob uma exponencial negativa ou "J" invertido, indicando que a regeneração ocorre continuamente. No decorrer das mensurações observa-se a presença de $G$. klotzschiana com diâmetro inferior a 10 $\mathrm{cm}$, com alta frequência no ambiente hidromórfico, ou seja, há uma tendência que esses indivíduos venham a se tornar ingressos nas próximas remedições.

A espécie apresentou aumento considerável no número de indivíduos ao longo das mensurações, o que se deve a alta taxa de ingresso e a ausência de mortalidade ao longo das mensurações, conforme ilustrado na Figura 1 para os anos de 2007, 2010 e 2013 respectivamente.

Em todos os períodos de mensuração, a Gymnanthes klotzschiana apresentou distribuição em "J" invertido, com a maioria dos indivíduos nas menores classes de diâmetro, característica de florestas multiespecíficas e multiâneas (STEPKA et al., 2010). Os diâmetros médios obtidos foram de 15,$37 ; 16,28$ e 17,31 cm (2007, 2010 e 2013, respectivamente). Analisando os gráficos, verifica-se que houve aumento considerável de indivíduos nas duas primeiras classes, devido principalmente as árvores ingressantes, proporcionando um aumento de $113,3 \%$ na população de Gymnanthes klotzschiana na última medição em relação a 2007. 

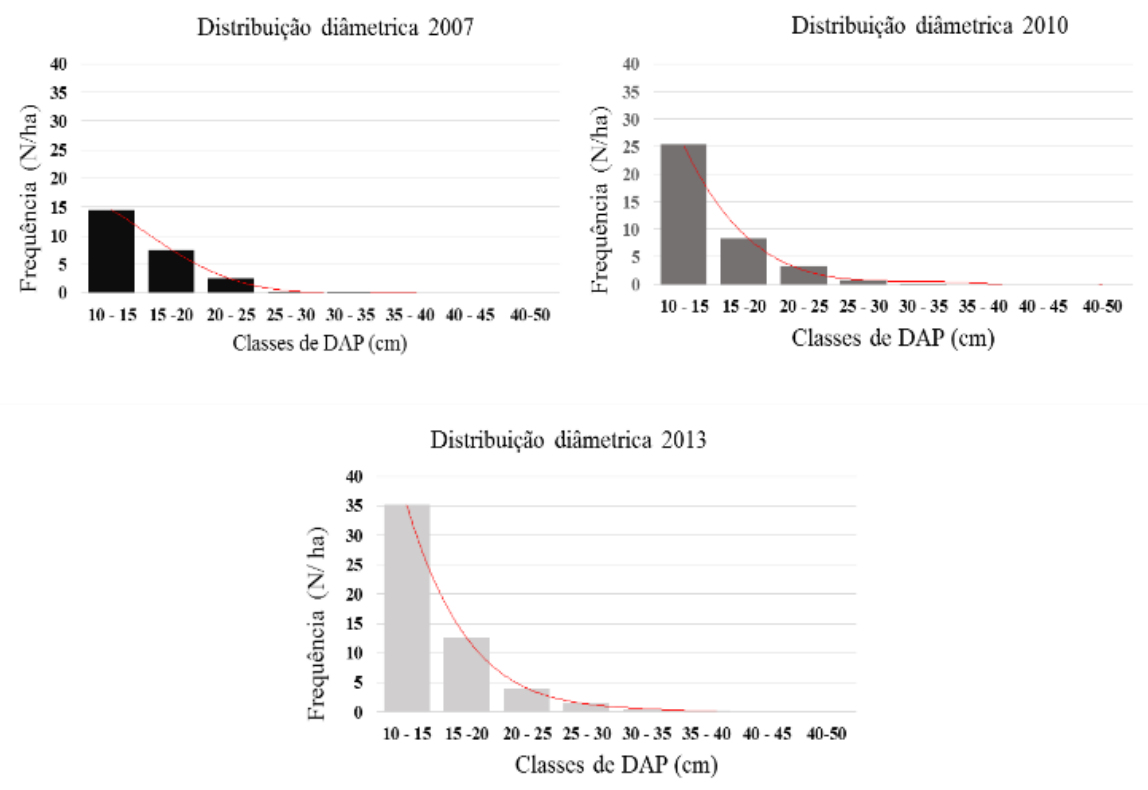

FIGURA 1 - Distribuição diamétrica de Gymnanthes klotzschiana nos anos de 2007, 2010 e 2013.

Santos (2014) encontrou para a mesma espécie o diâmetro médio de $15,01 \mathrm{~cm}$, com uma densidade de 35 indivíduos/ha. Esses valores aproximam dos resultados encontrados na medição de 2007, em que a densidade encontrada foi de 25,1 indivíduos/ha, considerando apenas a área de aluvial do fragmento.

Andrzejewski (2016), descreve a estrutura e florística de dois fragmentos ripários no noroeste do Rio Grande do Sul. Os resultados são similares aos encontrados neste trabalho, evidenciando a maior frequência nas duas primeiras classes de diâmetro e sua presença em classes de até $45 \mathrm{~cm}$ de diâmetro.

Essa característica reforça que a floresta tem alta capacidade de se renovar em meio a alterações climáticas ou perturbações antrópicas e processos de aberturas de clareiras, com certo equilíbrio entre ingresso e mortalidade.

\section{Análise estrutural}

Santos (2014), descreve o comportamento das espécies no Capão da Engenharia Florestal, o qual foi dividido em quatro fisionomias, onde Gymnanthes klotzschiana concerniu à floresta aluvial, caracterizado pelo baixo número de espécies com crescimento lento em áreas inundáveis. Algumas espécies mostraram um certo agrupamento com outras espécies.

No caso do branquilho, Santos (2014) conclui que a espécie apresenta alta correlação com a Schinus terebinthifolius além de se desenvolver de forma agrupada. Lingner et al. (2007), encontrou resultados que comprovam o alto grau de importância de Gymnanthes klotzschiana dentro da Floresta ombrófila mista aluvial, devido à sua alta frequência em relação as outras espécies, bem como sua alta capacidade de adaptação em regiões inundáveis.
Portanto, a partir de um ranking, estabelecido com base nos maiores índices de valor de cobertura, foi possível avaliar as características fitossociológicas e sua dinâmica no decorrer das mensurações. Ao todo foram mensurados 8.979 indivíduos em 2007 e 9.625 indivíduos em 2013, resultando em um aumento de $7,19 \%$ na população total do fragmento.

A população apresentou no ano de 2007 uma densidade de 588 indivíduos/ha, enquanto no ano de 2013 a densidade aumentou para 631 indivíduos/ha. As espécies que merecem destaque quanto ao maior número de indivíduos/ha foram: Casearia sylvestris $(90,62)$, Luehea divaricata $(44,95)$, Ocotea puberula $(27,89)$, Jacaranda puberula $(27,76)$, Symplocos tetrandra $(26,18)$, Araucaria angustifolia $(21,85)$ e Allophylus edulis $(23,75)$.

Considerando apenas a área aluvial do fragmento duas espécies se destacam: Schinus terebinthifolius $(26,18)$ e a Gymnanthes klotzschiana $(16,80)$, sendo esses valores referentes ao ano de 2013, similares aos encontrados por Santos (2014). O número de indivíduos total/ha é relativamente baixo considerando alguns estudos realizados por Rondon Neto et al. (2002) que encontraram valores estimados de 1.067 indivíduos/ha, usando a metodologia por meio de amostragem. Watzlawick et al. (2011), constataram uma densidade de 567 indivíduos/ha em uma área localizada em Rebouças (PR).

Os valores de densidade variam conforme metodologia adotada, o nível de conservação da área, visto que em áreas muito antropizadas as espécies pioneiras tendem a obter maiores valores enquanto as espécies clímax possuem menor densidade. As condições de sítio também alteram os resultados de um local para outro.

A área basal do fragmento passou de $21,55 \mathrm{~m}^{2}$ ha $^{-1}$ em 2007 para 25,13 $\mathrm{m}^{2} \mathrm{ha}^{-1}$ em 2013, dos quais a Araucaria angustifolia compôs $5,91 \mathrm{~m}^{2} \mathrm{ha}^{-1}$, enquanto que Gymnanthes klotzschiana obteve crescimento em área 
basal de 0,41 $\mathrm{m}^{2} \mathrm{ha}^{-1}$. Esses valores são próximos aos encontrados por Roik (2012) em seu trabalho realizado na FLONA de Irati (PR), em que os valores de área basal encontrados para 2011 de $30,56 \mathrm{~m}^{2} \mathrm{ha}^{-1}$, porém com taxa de incremento menor que a encontrada no presente estudo. Esse fato pode ser explicado pela maior taxa de ingresso e ao estágio do fragmento, ou seja, o fragmento do Capão da Engenharia Florestal está em estágio intermediário, enquanto que a maioria dos trabalhos realizados em outras regiões possuem floresta em estágio mais avançado.
$\mathrm{O}$ valor de cobertura expressa a importância da espécie dentro de um povoamento, levando em consideração a frequência, densidade e dominância da espécie. Estes valores são dinâmicos ao longo dos anos, uma vez que o crescimento em área basal, bem como o ingresso e/ou a mortalidade dos indivíduos alteram diretamente o valor de cobertura. Desta forma algumas espécies se mostraram uma evolução ao longo das medições enquanto outras permaneceram estáveis, ou até mesmo houve redução, devido principalmente ao índice de mortalidade (Figura 2).

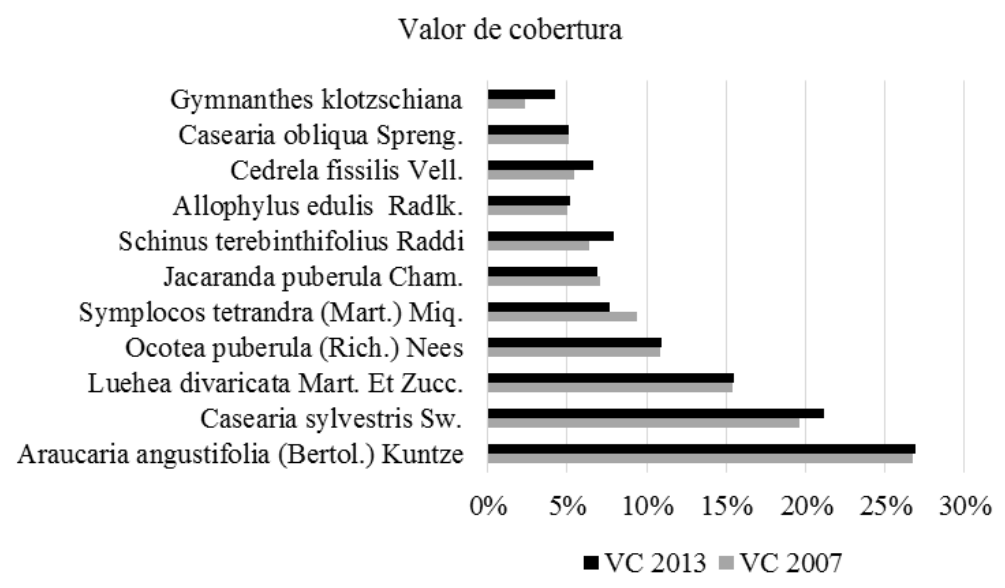

FIGURA 2 - Valor de cobertura nos anos de 2007 e 2013.

Os resultados fitossociológicos obtidos entre os anos de 2007 e 2013 estão descritos na Tabela 2. Dentre as espécies apresentadas no gráfico, Gymnanthes klotzschiana obteve o maior aumento relativo a seu valor de cobertura. Isso se deve principalmente à alta taxa de ingresso da espécie, aumentando sua densidade relativa e sua dominância. Desta forma a espécie se mostrou com alto potencial de regeneração e adaptação às áreas inundáveis, além de ter um comportamento diferenciado em relação a outras espécies pioneiras, devido sua longevidade, e desta forma a espécie prepara a área para que outras espécies se estabeleçam em melhores condições.

\section{Crescimento}

Os resultados encontrados mostram um aumento constante no número de Gymnanthes klotzschiana entre as três medições, passando de 120 para 256 árvores, consequentemente houve um incremento considerável em área basal entre as medições passando de $3,26 \mathrm{~m}^{2}$ para 6,2 $\mathrm{m}^{2}$. A taxa de incremento periódico anual em diâmetro passou de 0,31 cm/ano para 0,34 cm/ano, e o incremento periódico anual em área basal passou de $0,0280 \mathrm{~m}^{2} \mathrm{ha}^{-1}$ para $0,0397 \mathrm{~m}^{2} \mathrm{ha}^{-1}$.

A taxa de ingresso aumentou gradativamente enquanto que não houve mortalidade no período de medições. Um total de 62 indivíduos ingressaram no ano de 2010 e 74 no ano de 2013, resultando em um acréscimo na área basal de $0,69 \mathrm{~m}^{2}$ e $1,04 \mathrm{~m}^{2}$ respectivamente. Os diâmetros médios obtidos nas medições foram de 15,37 $\mathrm{cm}, 16,28 \mathrm{~cm} \mathrm{e} \mathrm{17,31} \mathrm{cm} \mathrm{em} \mathrm{2007,} 2010$ e 2013, respectivamente.

Resultados muito semelhantes em relação ao crescimento foram encontrados por Cubas (2011) para a espécie, obtendo um incremento periódico anual de 0,23 $\mathrm{cm}$ em um levantamento realizado na Floresta Nacional de Três Barras. Para área basal, esse autor encontrou IPA de $0,0120 \mathrm{~m}^{2} \mathrm{ha}^{-1}$, sendo próximo aos encontrados no Capão da Engenharia Florestal. A Tabela 3, mostra de forma mais detalhada os dados de crescimento de algumas espécies de maior valor de importância para o fragmento estudado.

Esses resultados mostram que a população da espécie está em pleno crescimento, porém como se trata de um fragmento com indivíduos de várias idades, não se pode afirmar que a espécie atingiu sua senilidade, visto que alguns indivíduos podem estar em estágio juvenil enquanto outros em estágio senil. Em comparação com a Schinus terebinthifolius, espécie com características semelhantes a Gymnanthes klotzschiana, também apresentou um aumento na taxa de incremento, porém houve mortalidade, refletindo em uma população com características pioneiras.

As duas espécies pertencem ao grupo da Floresta Ombrófila Mista como descrito por Santos (2014), porém a $S$. terebinthifolius ocorre em bordadura por todo o fragmento, já G. klotzschiana não apresenta indivíduos fora da região hidromórfica. Esse fator explica sua maior longevidade e a maior taxa de ingresso no local, em relação a $S$. terebinthifolius. 
Análise estrutural e...

KIERAS, W. S. et al. (2018)

TABELA 2 - Resultados fitossociológicos obtidos entre 2007 e 2013.

Resultados fitossociológicos obtidos no ano de 2007

\begin{tabular}{|c|c|c|c|c|c|c|c|c|c|c|}
\hline Espécies & $\mathrm{N}^{\mathrm{o}}$ árv & $\mathrm{G}\left(\mathrm{m}^{2}\right)$ & DA & $\begin{array}{l}\text { DR } \\
(\%)\end{array}$ & DoA & $\begin{array}{c}\text { DoR } \\
(\%)\end{array}$ & FA & $\begin{array}{l}\text { FR } \\
(\%)\end{array}$ & $\mathrm{VI}(\%)$ & $\begin{array}{l}\mathrm{VC} \\
(\%)\end{array}$ \\
\hline Araucaria angustifolia (Bertol.) Kuntze & 333 & 75,66 & 21,85 & 3,70 & 4,98 & 23,04 & 80,00 & 2,74 & 9,82 & 26,74 \\
\hline Luehea divaricata Mart. Et Zucc. & 654 & 26,68 & 42,91 & 7,26 & 1,76 & 8,12 & 84,29 & 2,88 & 6,09 & 15,39 \\
\hline Ocotea puberula (Rich.) Nees & 433 & 19,90 & 28,41 & 4,81 & 1,31 & 6,06 & 88,57 & 3,03 & 4,63 & 10,87 \\
\hline Symplocos tetrandra (Mart.) Miq. & 482 & 14,38 & 31,63 & 5,35 & 0,95 & 4,38 & 55,71 & 1,91 & 3,88 & 9,73 \\
\hline Jacaranda puberula Cham. & 411 & 8,12 & 26,97 & 4,57 & 0,53 & 2,47 & 75,71 & 2,59 & 3,21 & 7,04 \\
\hline Schinus terebinthifolius Raddi & 348 & 8,33 & 22,83 & 3,87 & 0,55 & 2,54 & 68,57 & 2,34 & 2,92 & 6,40 \\
\hline Allophylus edulis Radlk. & 316 & 4,83 & 20,73 & 3,51 & 0,32 & 1,47 & 77,14 & 2,64 & 2,54 & 4,98 \\
\hline Cedrela fissilis Vell. & 191 & 10,86 & 12,53 & 2,12 & 0,71 & 3,31 & 62,86 & 2,15 & 2,53 & 5,43 \\
\hline Casearia obliqua Spreng. & 294 & 5,86 & 19,29 & 3,27 & 0,39 & 1,78 & 68,57 & 2,34 & 2,46 & 5,05 \\
\hline Gymnanthes klotzschiana (Müll. Arg.) & 120 & 3,26 & 7,87 & 1,33 & 0,21 & 0,99 & 25,71 & 0,88 & 1,07 & 2,33 \\
\hline
\end{tabular}

Resultados fitossociológicos obtidos no ano de 2010

\begin{tabular}{|c|c|c|c|c|c|c|c|c|c|c|}
\hline Espécie & $\mathrm{N}^{\circ}$ árv & $\mathrm{G}\left(\mathrm{m}^{2}\right)$ & DA & $\begin{array}{l}\text { DR } \\
(\%)\end{array}$ & DoA & $\begin{array}{c}\text { DoR } \\
(\%)\end{array}$ & FA & $\begin{array}{l}\text { FR } \\
(\%)\end{array}$ & $\mathrm{VI}(\%)$ & $\begin{array}{l}\mathrm{VC} \\
(\%) \\
\end{array}$ \\
\hline Araucaria angustifolia (Bertol.) Kuntze & 333 & 82,32 & 21,85 & 3,61 & 5,42 & 22,86 & 80,00 & 2,82 & 9,77 & 26,48 \\
\hline Luehea divaricata Mart. Et Zucc. & 677 & 30,90 & 44,42 & 7,35 & 2,03 & 8,58 & 80,00 & 2,82 & 6,25 & 15,93 \\
\hline Ocotea puberula (Rich.) Nees & 429 & 23,06 & 28,15 & 4,66 & 1,52 & 6,41 & 90,00 & 3,17 & 4,74 & 11,06 \\
\hline Symplocos tetrandra (Mart.) Miq. & 479 & 15,56 & 32,81 & 5,43 & 1,02 & 4,32 & 44,29 & 1,56 & 3,77 & 9,75 \\
\hline Schinus terebinthifolius Raddi & 372 & 11,81 & 24,41 & 4,04 & 0,78 & 3,28 & 67,14 & 2,37 & 3,23 & 7,32 \\
\hline Jacaranda puberula Cham. & 424 & 9,24 & 27,82 & 4,60 & 0,61 & 2,57 & 70,00 & 2,47 & 3,21 & 7,17 \\
\hline Allophylus edulis Radlk. & 351 & 5,33 & 23,03 & 3,81 & 0,35 & 1,48 & 77,14 & 2,72 & 2,67 & 5,29 \\
\hline Myrcia hatschbachii D. Legrand & 207 & 9,99 & 13,58 & 2,25 & 0,66 & 2,77 & 62,86 & 2,22 & 2,41 & 5,02 \\
\hline Casearia obliqua Spreng. & 304 & 6,54 & 19,94 & 3,10 & 0,43 & 1,82 & 64,29 & 2,27 & 2,40 & 4,92 \\
\hline Gymnanthes klotzschiana (Müll. Arg.) & 182 & 4,40 & 11,94 & 1,98 & 0,29 & 1,22 & 24,29 & 0,86 & 1,35 & 3,20 \\
\hline
\end{tabular}

Resultados fitossociológicos obtidos no ano de 2013

\begin{tabular}{|c|c|c|c|c|c|c|c|c|c|c|}
\hline Espécie & $\mathrm{N}^{\mathrm{o}}$ árv & $\mathrm{G}\left(\mathrm{m}^{2}\right)$ & DA & $\begin{array}{l}\mathrm{DR} \\
(\%)\end{array}$ & DoA & $\begin{array}{c}\text { DoR } \\
(\%)\end{array}$ & FA & $\begin{array}{l}\text { FR } \\
(\%)\end{array}$ & $\mathrm{VI}(\%)$ & $\begin{array}{l}\mathrm{VC} \\
(\%)\end{array}$ \\
\hline Araucaria angustifolia (Bertol.) Kuntze & 333 & 89,78 & 21,85 & 3,45 & 5,91 & 23,44 & 80,00 & 2,51 & 9,80 & 26,89 \\
\hline Luehea divaricata Mart. Et Zucc. & 685 & 31,99 & 44,95 & 7,10 & 2,10 & 8,35 & 87,14 & 2,73 & 6,06 & 15,45 \\
\hline Ocotea puberula (Rich.) Nees & 425 & 25,05 & 27,89 & 4,40 & 1,65 & 6,54 & 91,43 & 2,86 & 4,60 & 10,94 \\
\hline Schinus terebinthifolius Raddi & 399 & 13,61 & 26,18 & 4,13 & 0,90 & 3,55 & 70,00 & 2,19 & 3,29 & 7,69 \\
\hline Symplocos tetrandra (Mart.) Miq. & 399 & 12,86 & 26,18 & 4,13 & 0,85 & 3,36 & 60,00 & 1,88 & 3,12 & 7,49 \\
\hline Jacaranda puberula Cham. & 423 & 9,72 & 27,76 & 4,38 & 0,64 & 2,54 & 75,71 & 2,37 & 3,10 & 6,92 \\
\hline Cedrela fissilis Vell. & 190 & 14,02 & 12,47 & 1,97 & 0,92 & 3,66 & 68,57 & 2,15 & 2,59 & 5,63 \\
\hline Allophylus edulis Radlk. & 362 & 5,61 & 23,75 & 3,75 & 0,37 & 1,46 & 80,00 & 2,51 & 2,57 & 5,22 \\
\hline Casearia obliqua Spreng. & 309 & 7,34 & 20,28 & 3,20 & 0,48 & 1,92 & 72,86 & 2,28 & 2,47 & 5,12 \\
\hline Gymnanthes klotzschiana (Müll. Arg.) & 256 & 6,20 & 16,80 & 2,65 & 0,41 & 1,62 & 27,14 & 0,85 & 1,71 & 4,27 \\
\hline
\end{tabular}

$\mathrm{N}^{\circ}$ árv: número total de indivíduos presentes na área de estudo. $\mathrm{G}\left(\mathrm{m}^{2}\right)$ : área basal total da espécie no fragmento em metros quadrados. DA: densidade absoluta. DR: densidade relativa. DoA: dominância absoluta. DoR: dominância relativa. FA: frequência absoluta. FR: frequência relativa. VI: valor de importância. VC: valor de cobertura. 
Análise estrutural e...

KIERAS, W. S. et al. (2018)

TABELA 3 - Resultados de crescimento obtidos entre os anos de 2007 - 2013.

\begin{tabular}{|c|c|c|c|c|c|c|c|c|c|c|}
\hline Espécies & Ano & № árv.* & $\mathrm{G}$ & $\mathrm{IPd}$ & IPAd & $\mathrm{IPg}$ & IPAg & IPAg/ha. & $\mathrm{M}$ & I \\
\hline \multirow{3}{*}{ Araucaria angustifolia (Bertol.) Kuntze } & 2007 & 333 & 75,66 & - & - & - & - & - & - & - \\
\hline & 2010 & 333 & 82,32 & 2,24 & 0,75 & 6,14 & 2,0467 & 0,1343 & 0 & 0 \\
\hline & 2013 & 333 & 89,78 & 2,95 & 0,98 & 7,77 & 2,5891 & 0,1699 & 0 & 0 \\
\hline \multirow{3}{*}{ Casearia sylvestris $S w}$. & 2007 & 1235 & 19,27 & - & - & - & - & - & - & - \\
\hline & 2010 & 1352 & 24,34 & 0,77 & 0,26 & 1,99 & 0,6635 & 0,0435 & 3 & 120 \\
\hline & 2013 & 1375 & 26,35 & 0,67 & 0,22 & 1,90 & 0,6327 & 0,0415 & 60 & 83 \\
\hline \multirow{3}{*}{ Luehea divaricata Mart. Et Zucc. } & 2007 & 654 & 26,68 & - & - & - & - & - & - & - \\
\hline & 2010 & 677 & 30,9 & 0,66 & 0,22 & 1,66 & 0,5530 & 0,0363 & 1 & 24 \\
\hline & 2013 & 685 & 31,99 & 0,66 & 0,22 & 1,62 & 0,5403 & 0,0355 & 9 & 17 \\
\hline \multirow{3}{*}{ Ocotea puberula (Rich.) Nees } & 2007 & 430 & 19,9 & - & - & - & - & - & - & - \\
\hline & 2010 & 429 & 23,06 & 1,62 & 0,54 & 2,56 & 0,8544 & 0,0561 & 1 & 0 \\
\hline & 2013 & 425 & 25,05 & 1,49 & 0,50 & 2,50 & 0,8317 & 0,0546 & 17 & 13 \\
\hline \multirow{3}{*}{ Schinus terebinthifolius Raddi } & 2007 & 348 & 8,33 & - & - & - & - & - & - & - \\
\hline & 2010 & 372 & 11,81 & 1,21 & 0,40 & 1,28 & 0,4265 & 0,0280 & 1 & 25 \\
\hline & 2013 & 399 & 13,61 & 1,40 & 0,47 & 1,87 & 0,6236 & 0,0409 & 22 & 49 \\
\hline \multirow{3}{*}{ Gymnanthes klotzschiana (Müll. Arg.) } & 2007 & 120 & 3,26 & - & - & - & - & - & - & - \\
\hline & 2010 & 182 & 4,4 & 0,94 & 0,31 & 0,40 & 0,1331 & 0,0280 & 0 & 62 \\
\hline & 2013 & 256 & 6,20 & 1,03 & 0,34 & 0,57 & 0,1887 & 0,0397 & 0 & 74 \\
\hline
\end{tabular}

*Espécie: binômio da espécie. Ano: Ano de mensuração. $\mathrm{N}^{\circ}$ árv: número total de indivíduos presentes na área de estudo. $\mathrm{G}$ $\left(\mathrm{m}^{2}\right)$ : área basal total da espécie no fragmento em metros quadrados. IPd: Incremento periódico diamétrico expresso em (cm). IPAd: Incremento periódico anual diamétrico expresso em (cm/ano). IPg: Incremento periódico em área transversal exmpresso em $\left(\mathrm{m}^{2}\right)$. IPAg: Incremento periódico anual em área transversal expresso em ( $\left.\mathrm{m}^{2} / \mathrm{ano}\right)$. IPAg/ha: Incremento periódico anual por ha em área transversal expresso em ( $\left.\mathrm{m}^{2} / \mathrm{ano} / \mathrm{ha}\right)$. M: Mortalidade ocorrida no presente ano de mensuração. I: Número de indivíduos ingressantes no presente ano de mensuração.

\section{Relação hipsométrica}

A avaliação e a modelagem de dados de altura em florestas inequiâneas é complexa, pela dificuldade de encontrar o ápice da copa, além do tempo de medição que é bem maior quando comparado a variável diâmetro.
Contudo, no ano de 2016 foi realizada a mensuração de altura total de todos os 256 indivíduos de Gymnanthes klotzschiana para auxiliar na descrição e modelagem da espécie (Figura 3).

\section{Relação h/d}

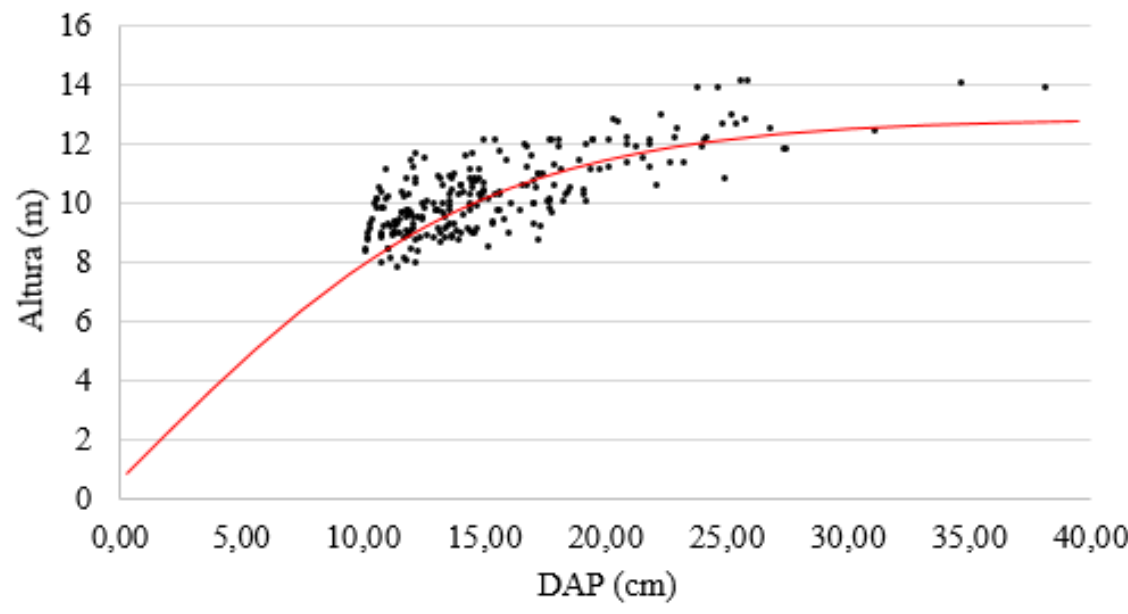

FIGURA 3 - Relação hipsométrica de Gymnanthes klotzschiana no ano de 2016. 
A linha de tendência obtida no gráfico acima, demonstra apenas uma simples modelagem hipsométrica, onde a distância dos pontos abaixo da curva é próxima ou igual aos pontos acima da curva. Essa relação mostra que apesar da espécie apresentar diferentes idades entre os indivíduos, apresenta uma boa correlação entre altura e DAP $(0,76)$, porém essa mesma relação hipsométrica não pode ser utilizada em outros períodos ou em outros

Henricken

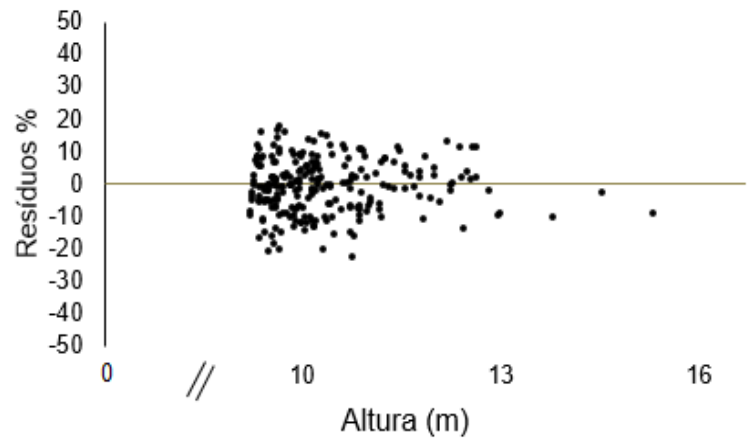

fragmentos, mesmo que seja para a mesma espécie, pois tanto a altura como diâmetro são variáveis dinâmicas e que se alteram em diferentes sítios, além de apresentarem diferentes idades em um mesmo fragmento.

$\mathrm{O}$ modelo que melhor representou a estimativa em altura para a G. klotzschiana no ano de 2016 foi o modelo de Trorey, conforme demonstrado na Figura 4 e Tabela 4.

FIGURA 4 - Distribuição de resíduos para ambos os modelos ajustados para Gymnanthes klotzschiana.

Dentre as duas equações testadas, a que melhor representou a estimativa de altura para a espécie foi a regressão de Trorey, pois apresentou maior coeficiente de determinação, bem como menor erro padrão de estimativa e valor de F calculado, além de uma distribuição de resíduos mais uniforme, sendo mais acurado e preciso em relação ao modelo de Henricksen (Tabela 4).

TABELA 4 - Comparação entre modelos ajustados para Gymnanthes klotzschiana.

\begin{tabular}{clccc}
\hline & Modelos & $\mathrm{R}^{2} \mathrm{a}_{j}{ }^{*}$ & Syx $(\%)$ & $\mathrm{F}_{\text {cal }}$ \\
\hline 1 & Henricksen & 0,58 & 8,26 & 329,95 \\
2 & Trorey & 0,59 & 8,19 & 167,86 \\
\hline
\end{tabular}

${ }^{*} \mathrm{R}^{2}{ }_{\text {aj }}=$ coeficiente de determinação ajustado, Syx = erro padrão da estimativa, $\mathrm{F}_{\text {cal }}=\mathrm{F}$ calculado, conforme teste de regressão.

A altura média encontrada para a espécie no ano de 2016 foi de $10,25 \mathrm{~m}$, porém essa altura varia muito em relação ao grau de inundação da área, ou seja, em áreas onde há inundação em períodos chuvosos (outubro fevereiro) foi constatado uma altura média menor de 9,48 $\mathrm{m}$, em relação as áreas em que não há inundação em nenhum período do ano, onde a altura média chegou a

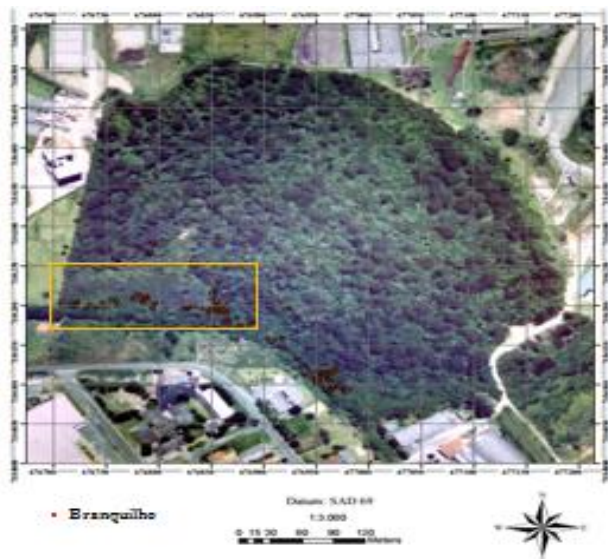

FIGURA 5 - Distribuição espacial da Gymnanthes klotzschiana no ano de 2007 (esquerda) e 2013 (direita). (Coordenadas

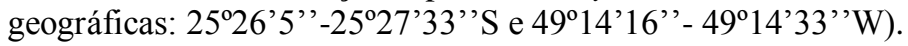

$11,17 \mathrm{~m}$. Por outro lado, a frequência de indivíduos é maior em áreas inundáveis, reforçando que a germinação da espécie é favorecida em solos hidromórficos. A Figura 5 ilustra esta situação, onde a taxa de ingresso é maior na área delimitada pelo retângulo, ou seja, na região de inundação.

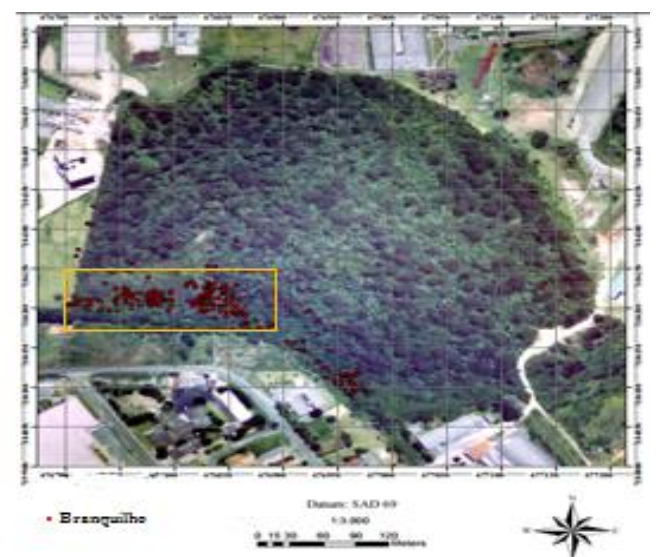




\section{CONCLUSÕES}

Gymnanthes klotzschiana ocorre exclusivamente em áreas hidromórficas, caracterizando seu alto valor de importância em florestas aluviais.

G. klotzschiana apresenta distribuição diamétrica em "J" invertido, desta forma a espécie está aumentando sua população e consequentemente o estado de conservação da fisionomia aluvial, propiciando melhores condições de luminosidade e do solo para a germinação e o desenvolvimento das espécies secundárias.

A G. klotzschiana não atingiu seu valor assintótico tanto para diâmetro quanto para área transversal, porém não é possível afirmar sua fase de crescimento, visto que os indivíduos possuem várias idades. A espécie apresenta uma baixa taxa de crescimento quando comparado com as espécies de alto valor de importância.

A equação de Trorey propiciou bons resultados para a estimativa de altura de G. klotzschiana em um fragmento de Floresta Ombrófila Mista.

\section{REFERÊNCIAS BIBLIOGRÁFICAS}

ANDRZEJEWSKI, C. Estrutura e florística de dois fragmentos ripários de floresta estacional decidual no noroeste do Rio Grande do Sul. 2016. 88 f. Dissertação (Mestrado em Engenharia Florestal) - Centro de Ciências Rurais, Universidade Federal de Santa Maria, RS, 2016.

AUGUSTYNCZIK, A.L.D. Avaliação do tamanho de parcelas $e$ intensidades de amostragem para a estimativa de estoque e estrutura horizontal em um fragmento de Floresta Ombrófila Mista. 2011. 164p. Dissertação (Mestrado em Engenharia Florestal) - Setor de Ciências Agrárias, Universidade Federal do Paraná, Curitiba, 2011.

CARVALHO, P.E.R. Espécies arbóreas brasileiras. Brasília: Embrapa Informação Tecnológica; Colombo: Embrapa Florestas, 2003. v.1, 1039 p.

CUBAS, R. Florística, estrutura e dinâmica em uma Floresta Ombrófila Mista no norte do estado de Santa Catarina. 2011. 133p. Dissertação (Mestrado em Ciências Florestais) - Universidade Estadual do Centro Oeste, Irati, 2011.

LINGNER，D.V.; OLIVEIRA，Y.M.M.; ROSOT， N.C.; DLUGOSZ, F.L. Caracterização da estrutura e da dinâmica de um remanescente de Floresta Ombrófila no Planalto Catarinense. Pesquisa Florestal Brasileira, Colombo, v.1, n.55, p.55-66, 2007.

LORENZI, H. Árvores brasileiras: manual de identificação e cultivo de plantas arbóreas nativas do Brasil. v.2. Nova Odessa: Plantarum, 1992. 368p.

MAACK, R. Geografia física do Estado do Paraná. $2^{a}$ ed. Rio de Janeiro: J. Olympio, 1981.

MÜELLER-DOMBOIS, D.; ELLENBERG, H. Aims and methods of vegetation ecology. New York: WILEY, J.; SONS. 1974.

NARVAES, I.S.; LONGHI, S.J.; BRENA, D.A. Florística e classificação da regeneração natural em Floresta Ombrófila Mista na floresta nacional de São Francisco de
Paula, RS. Ciência Florestal, Santa Maria, v.18, n.2, p.233-245, 2008.

ORELLANA, E. Funções densidade de probabilidade no ajuste da distribuição diamétrica de um fragmento de Floresta Ombrófila Mista. 2009. 122p. Dissertação (Mestrado em Ciências Florestais) - Universidade Estadual do Centro Oeste do Paraná, Irati, 2009.

ROIK, M. Dinâmica e modelagem do incremento diamétrico em fragmento de Floresta Ombrófila Mista na Floresta Nacional de Irati, Paraná. 2012. 141p. Dissertação (Mestrado em Manejo Florestal) Universidade Estadual do Centro Oeste, Irati, 2012.

RONDON NETO, R.M.; KOZERA, C.; ANDRADE, R.R. de; CECY, A. T.; HUMMES, P.A.; FRITZSONS, E.; CALDEIRA, M.V.W.; MACIEL, M. de N.M.; SOUZA, M.K.F. Caracterização florística e estrutural de um fragmento de floresta ombrófila mista, em Curitiba, PR Brasil. Revista Floresta, Curitiba, v.32, n.1, p.3-16, 2002. SANTOS, A.A.P dos. Avaliação florística e estrutural de uma Floresta Ombrófila Mista montana urbana. 2014. 130p. Dissertação (Mestrado em Engenharia Florestal), Universidade Federal do Paraná, Curitiba. 2014. SEGER, C.D.; DLUGOSZ, F.L.; KURASZ, G.; MARTINEZ, D.T.; RONCONI, E.; MELO, L.A.N.; BITTENCOURT, S.M.; BRAND, M.A.; CARNIATTO, I.; GALVÃO, F.; RODERJAN, C.V. Levantamento florístico e análise fitossociológica de um remanescente de floresta ombrófila mista localizado no município de pinhais, Paraná - Brasil. Revista Floresta, Curitiba, v.35, n.2, p.291-302, 2005.

SILVA, S.M.; SILVA, F.C.; VIEIRA, A.O.S.; NAKAJIMA, J.N.; PIMENTA, J.A.; COLLI, S. Composição florística e fitossociológica do componente arbóreo das florestas ciliares da bacia do Rio Tibagi: 2 . Várzea do Rio Bitumirim, município de Ipiranga, PR. Revista do Instituto Florestal, São Paulo, v.5, n.1, p.191198, 1992.

STEPKA, T.F.; DIAS, A.N.; FIGUEIREDO FILHO, A.; MACHADO, S.D.A.; SAWCZUK, A.R. Prognose da estrutura diamétrica de uma Floresta Ombrófila Mista com os métodos razão de movimentos e matriz de transição. Pesquisa Florestal Brasileira, Colombo, v.30, n.64, p.327-335, 2010.

VELOSO, H.P.; RANGEL FILHO; A.L.R.; LIMA, J.C.A. Classificação da vegetação brasileira, adaptada a um sistema universal. Rio de Janeiro: IBGE, Departamento de Recursos Naturais e Estudos Ambientais, 1991. 124p.

WATZLAWICK, L.F.; ALBUQUERQUE, J.M.; REDIN, C.G.; LONGHI, R.V.; LONGHI, S.J. Estrutura, diversidade e distribuição espacial da vegetação arbórea na floresta ombrófila mista em sistema faxinal, Rebouças (PR). Ambiência, Guarapuava, v.7, n.3, p.415-427, 2011. 